\title{
Arsenicosis case identification, diagnosis and management protocol for early patient medicare administration and treatment
}

\author{
Islam-ul-haque \\ Ecological Sustainability through Environment Protection Services (Eco-STEPS), Inc, Islamabad-Pakistan
}

Email address:

Islamhaq3@yahoo.com

To cite this article:

Islam-ul-haque. Arsenicosis Case Identification, Diagnosis and Management Protocol for Early Patient Medicare Administration and Treatment. International Journal of Environmental Monitoring and Analysis. Special Issue: Ground Water Arsenic Contamination and Action Plan for Mitigation. Vol. 3, No. 3-1, 2015, pp. 1-9. doi: 10.11648/j.ijema.s.2015030301.11

\begin{abstract}
Many countries in the world, especially South Asia e.g., Bangladesh, India, Nepal, Vietnam, China and Myanmar are facing ground water arsenic contamination problems and it has been recognized as an emerging threat and challenge to public health (Ahmad et al, 2004). Pakistan, following the arsenic crisis in Bangladesh and in other neighboring countries, has recognized the need of assessing drinking water quality for arsenic contamination in late nineties (PCRWR 2002). Ground water arsenic contamination has emerged as a serious socio-economic and human health concerns all over the world, including Pakistan. Likewise, around 25-36\% population of two provinces in Pakistan is exposed to drinking water arsenic contamination over $10 \mathrm{ppb}$. It may be reasonable to disregard the presence of some arsenic in the water, but beyond 50 ppb is considered dangerous (NAPAM 2005). Keeping in view the adverse impacts of arsenic contamination on human health, various initiatives by different governmental and non-governmental departments and organizations were taken, without resource integration and prudent coordination mechanisms amongst the various stakeholders (IUCN, 2007). These practices resulted in wastages of scarce resources, rather than pooling up all the resources and getting maximum. During this process some experiences have been gained related to planning, implementation, monitoring and management of arsenic mitigation. As arsenic contamination causes serious health issues, therefore, the timely identification and diagnosis of arsenicosis patients remained a major problem due to absence of standard operating procedures / protocols . The arsenicosis patients identification was being observed and realized after the appearance of arsenicosis symptoms, like skin pigmentation etc, on the body parts of the effected persons. Over and above, there was no set procedures to administer the treatment and case management of such arsenicosis patients. Therefore, well designed protocols or standard operating procedures have been documented which may assist while carrying out identification of suspected arsenicosis patients. This paper will provide road map for arsenicosis diagnostic procedures, treatment administration, case management and behavioral change communication by creating awareness amongst such affected communities, prior getting prey of arsenicosis victim.
\end{abstract}

Keywords: Arsenicosis Diagnosis Protocol, Arsenic mitigation approaches, Ground Water Quality

\section{Introduction}

\subsection{Arsenic Chemistry}

Arsenic is an element that occurs naturally in rock beds/sediments, soil, water, air, plants, and in animals. Being a metalloid, it posses metallic and nonmetallic chemical and physical properties (Saldivar et al, 2009). The primary valence states for arsenic are $0,-3,+3$ and +5 . Arsenic is found in nature to a small extent in its elemental form $(0$ valence), it occurs most often as inorganic and organic compounds in either the As (III) (+3) or As (V) $(+5)$ valence states. Mobilization of arsenic in groundwater is governed by the geochemical processes involving leaching of continental rocks as well as sediments. Anthropogenic inputs particularly due to the application and use of arsenical wood preservatives as well as pesticides could also lead to significant emission of arsenic in groundwater, especially under anoxic conditions (Bhattacharya et al. 1996, 1998). The risk for arsenic contamination in groundwater is, therefore, 
higher than in surface waters. Arsenic contaminated groundwater as the primary source of drinking water in several areas has particularly accentuated the problem because of the effects of arsenic exposure on human health (Bhattacharya et al, 1998).

\subsection{The ill Impacts of Arsenic Contamination on Human Health and on Socio-Economic Conditions - Arsenicosis}

The chronic exposure to arsenic contamination causes various diseases to human and victims / effected persons are termed as Arsenicosis, which is the effect of arsenic poisoning. The chronic exposure normally ranges from 5 to 20 years and termed as chronic exposure . Drinking arsenicrich water, whatever is the period rang, results in various health effects including skin problems (such as color changes on the skin, and hard patches on the palms and soles of the feet) (Dhungana, 2012). Thickening lesions once developed are irreversible even with the restoration of safe drinking water for a long time. Long term exposure also leads to skin cancer, cancers of the bladder, kidney and lungs, and diseases of the blood vessels of the legs and feet, and possibly also diabetes, high blood pressure and reproductive disorders (Islam et al, 2012). Inpsite of wide ranging ill impacts on human health, there has been no set procedures/protocols being followed for early detection and timely arsenicosis case administration and treatment .

\section{Literature Review}

\subsection{Natural Arsenic Sources}

There are several natural sources as well as anthropogenic activities that may introduce arsenic into food and drinking water. The primary natural sources include geologic formations (e.g. rocks, soil, and sedimentary deposits), geothermal activity, and volcanic activities. Arsenic and its compounds comprise 1.5-2 percent of the earth's crust (Welch, personal communication). While concentrations of arsenic in the earth's crust vary, the average concentrations are generally reported to range from 1.5 to $5 \mathrm{mg} / \mathrm{kg}$. Arsenic is a major constituent of many mineral species in igneous and sedimentary rocks. It is commonly present in the sulfide ores of metals including copper, lead, silver, and gold. There are over 100 arsenic-containing minerals, including arsenic pyrites (e.g., FeAsS), realgar (AsS), lollingite $\left(\mathrm{FeAs}_{2}, \mathrm{Fe}_{2} \mathrm{As}_{3}\right.$, $\left.\mathrm{Fe}_{2} \mathrm{As}_{5}\right)$, and orpiment $\left(\mathrm{As}_{2} \mathrm{~S}_{3}\right)$. Geothermal water can be a source of inorganic arsenic in surface water and ground water .( Welch et al ,1988) identified fourteen areas in the western United States where dissolved arsenic concentrations ranged from 80 to $15,000 \mu \mathrm{g} / \mathrm{L}$.

In China, chronic exposure to arsenic contaminated drinking water has shown appearance of gangrene, known as 'black foot disease' (WHO 2001). This disease has not been observed in other parts of the world, and it is possible that malnutrition contributes to its development. However, studies in several countries have demonstrated that arsenic causes other less severe forms of peripheral vascular disease. The common symptoms of conjunctivitis, melanosis, deigmentation, keratosis and hyperkeratosis; cases of gangrene and malignan neoplasms were also observed.

\subsection{Industrial Sources of Arsenic}

Major present and past sources of arsenic include wood preservatives, agricultural uses, industrial uses, mining and smelting. The human impact on arsenic levels in water depends on the level of human activities, the distance from the pollution sources, and the dispersion and fate of the arsenic that is released. The production of chromate copper arsenate (CCA), an inorganic arsenic compound and wood preservative, accounts for approximately 90 percent of the arsenic used annually by industry in the United States (USGS, 1998; USGS, 1999).

\subsection{Dietary Sources of Arsenic}

Arsenic occurs naturally, the entire population is exposed to low levels of arsenic through food, water, air, and contact with soil. The National Research Council report (NRC, 1999) assumed that for fish and seafood, inorganic arsenic is 10 percent of the total arsenic and that other food contains, are entirely inorganic arsenic. The NRC report characterizes inorganic arsenic intake from food in the U.S. as being 1.3 $\mu \mathrm{g} /$ day for infants under one-year old, $4.4 \mu \mathrm{g}$ /day for twoyear olds, almost $10 \mu \mathrm{g}$ /day for 25-30 year-old males, with a maximum of $12.5 \mu \mathrm{g}$ /day for 60-65 year-old males (females had lower arsenic intake in every age group). Similarly, the 2 L/day assumption of adult drinking water intake used to develop the Maximum Contaminant Level Goal (MCLG) rather than representing intake by the average person, represents that of a person in the 90th percentile.

\subsection{Environmental Sources of Arsenic}

Internal exposure after skin contact with water or soil containing arsenic or inhalation of arsenic from air is believed to be low. Studies of inorganic arsenic absorption from skin from cadavers estimated 0.8 percent uptake from soil and 1.9 percent uptake from water over a 24-hour period (Wester, et. al., 1993). The EPA's arsenic health assessment document for the Clean Air Act (US EPA, 1984) cited respiratory arsenic as being about $0.12 \mu \mathrm{g}$ /day from a daily ventilation rate of $20 \mathrm{~m} \backslash 3 \backslash$ using a 1981 national average arsenic concentration of $0.006 \mu \mathrm{g} / \mathrm{m} \backslash 3 \backslash$.

\subsection{Arsenic Prevalence - Pakistan}

In southern part of Punjab province -Pakistan, 1.3 million people are exposed to drinking water arsenic contamination and the worst effected districts are, Multan, Bahwalpur, Rahim Yar khan and Muzaffargarh (PCRWR (2003). In the province of Sindh (Pakistan), Khairpur and Dadu are the worst effected districts (centre for environment protection studies) (SAFWCO 2003). The arsenic prevalence in Pakistan is described in figure-1, below; 


\section{The total population of these 656 villages is $6,173,680$ that are at risk from exposure to arsenic in their water supply.}

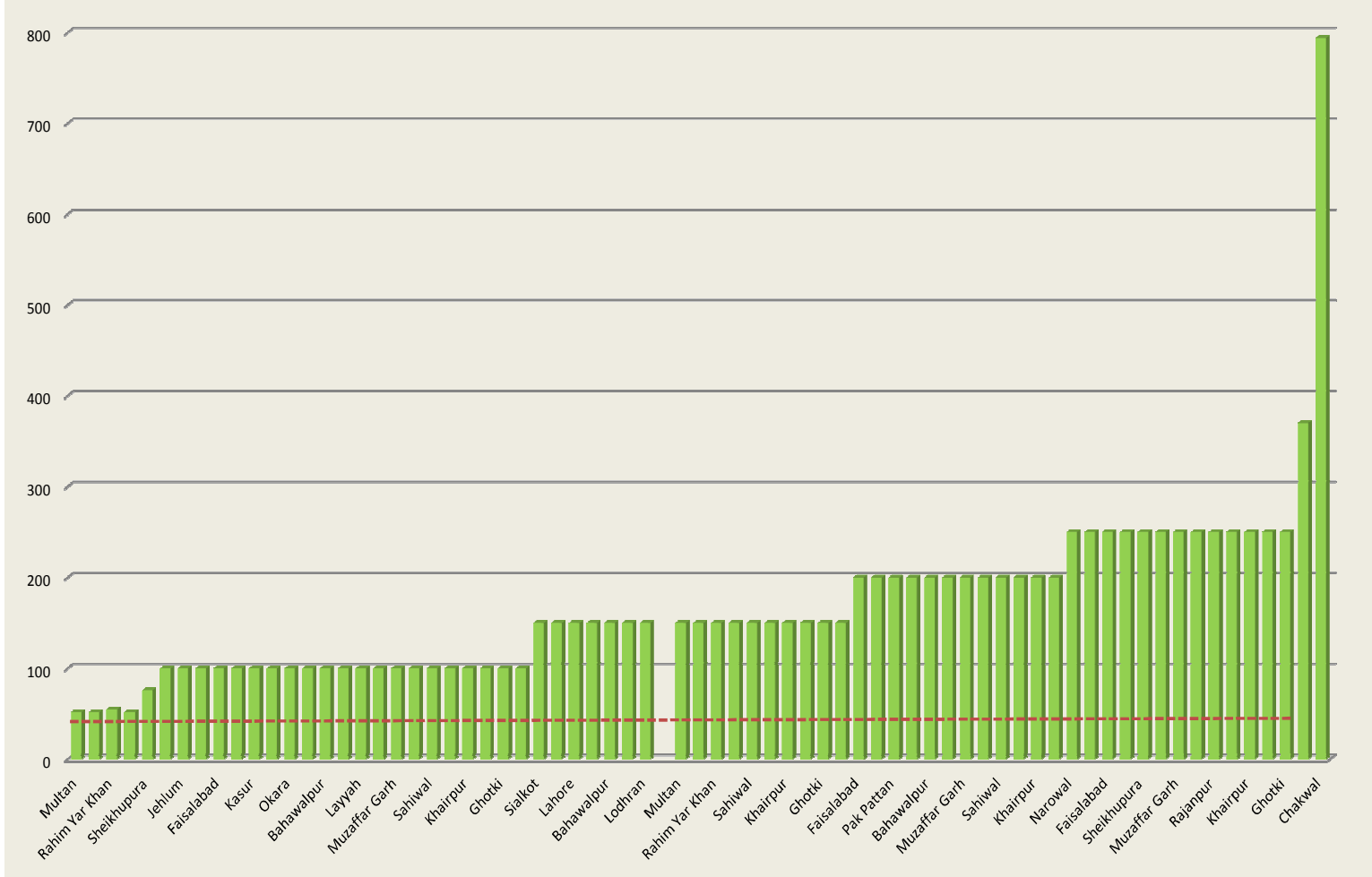

Figure 1. Arsenic contamination status in 656 villages of Pakistan

\section{Objectives}

The main objectives of this research paper are as under;

- To review and assess the extent of ill impacts on human health due arsenic contamination exposure

- To evolve guidelines for identification of arsenicosis symptoms and diagnosis procedures and methods.

- To chalk out arsenicosis protocol, required for efficient case management \& treatment administration and evolving of behavioral change communication strategy for adopting safe health and hygiene practices.

\section{Methodology}

The information on various aspects of arsenic contamination were obtained from field and laboratory testing, meeting and interacting with community from arsenic prevalence areas of Pakistan. Meeting with suspected arsenicosis individuals revealed that there are no set procedures being followed for identification and confirmation of arsenicosis patients. Extensive meeting with health department were carried out to ascertain the presence of required expertise and health care facilities for identification of such arsenicosis patients.

Excessive literature review was carried out and it was noted that different approaches are being practiced for arsenicosis patient management and there is no uniformity, in procedures and integration of efforts, being followed, by various government health departments and non-government organizations.

This necessitated for drawing up arsenicosis protocols for early identification of arsenicosis patient treatment and case administration.

\section{Results and Discussion}

Drinking water arsenic contamination has emerged as a serious health concern for the people who are exposed to arsenic contamination. The detailed assessment of ill impacts of arsenic contamination on human health are as under;

\subsection{Adverse Impacts of Drinking Water Arsenic Contamination on Human Health}

1. Chronic arsenic poisoning, occurs after long-term 
exposure through drinking- water is very different to acute poisoning. Immediate symptoms on an acute poisoning typically include vomiting, esophageal and abdominal pain, and bloody "rice water" diarrhea. Chelation therapy may be effective in acute poisoning but should not be used against long-term poisoning.

2. The symptoms and degrees of arsenicosis developed are differ between individuals, and population groups. Currently, there is no universal definition of the disease caused by arsenic. This complicates the assessment process in identifying the arsenicosis patients . Similarly, there is no method to identify those cases of internal cancer that were caused by arsenic from cancers induced by other factors.

3. Long-term exposure to arsenic by consuming arsenic contaminated drinking-water results in skin hyper and hypo-pigmentation and hyperkeratosis and skin cancer as well as possible cancer of lungs, urinary bladder and kidney.

4. Increased risks of lungs and bladder cancer and of arsenic-associated skin lesions have been observed at drinking-water arsenic concentrations of less than $0.05 \mathrm{mg} / \mathrm{L}$.

5. Absorption of arsenic through the skin is minimal and thus hand-washing, bathing, laundry, etc. with water containing arsenic do not pose human health risk.

6. Following long-term exposure, the first changes are usually observed in the skin are pigmentation changes, and then hyperkeratosis. Cancer is a late phenomenon, and usually takes more than 10 years to develop.

7. The relationship between arsenic exposure and other health effects is not clear. For example, some studies have reported hypertensive and cardiovascular disease, diabetes and reproductive effects, linked with arsenic contamination.

8. Exposure to arsenic via drinking-water has been shown to cause a severe disease of blood vessels leading to gangrene in China (Province of Taiwan), known as 'black foot disease'. This disease has not been observed in other parts of the world, and it is possible that malnutrition contributes to its development. However, studies in several countries have demonstrated that arsenic causes other, less severe forms of peripheral vascular disease.

9. Social Effects of Arsenicosis: In some rural villages, arsenicosis is given the name "Curse of God." This only hints at the social trauma wrought by arsenicosis, which in many instances far outweighs the physical pain and suffering. Entire villages are isolated and treated like leper colonies. Women are abandoned by their husbands, young women and men cannot get married, men lose their jobs, children are kept home from school to hide the disease.

10. According to some estimates, arsenic in drinkingwater will cause 200,000 -- 270,000 deaths from cancer in Bangladesh alone (NRC, 1998; Smith, et al, 2000). The photographs of arsenicosis cases are shown in figure- $2 \& 3$, below;
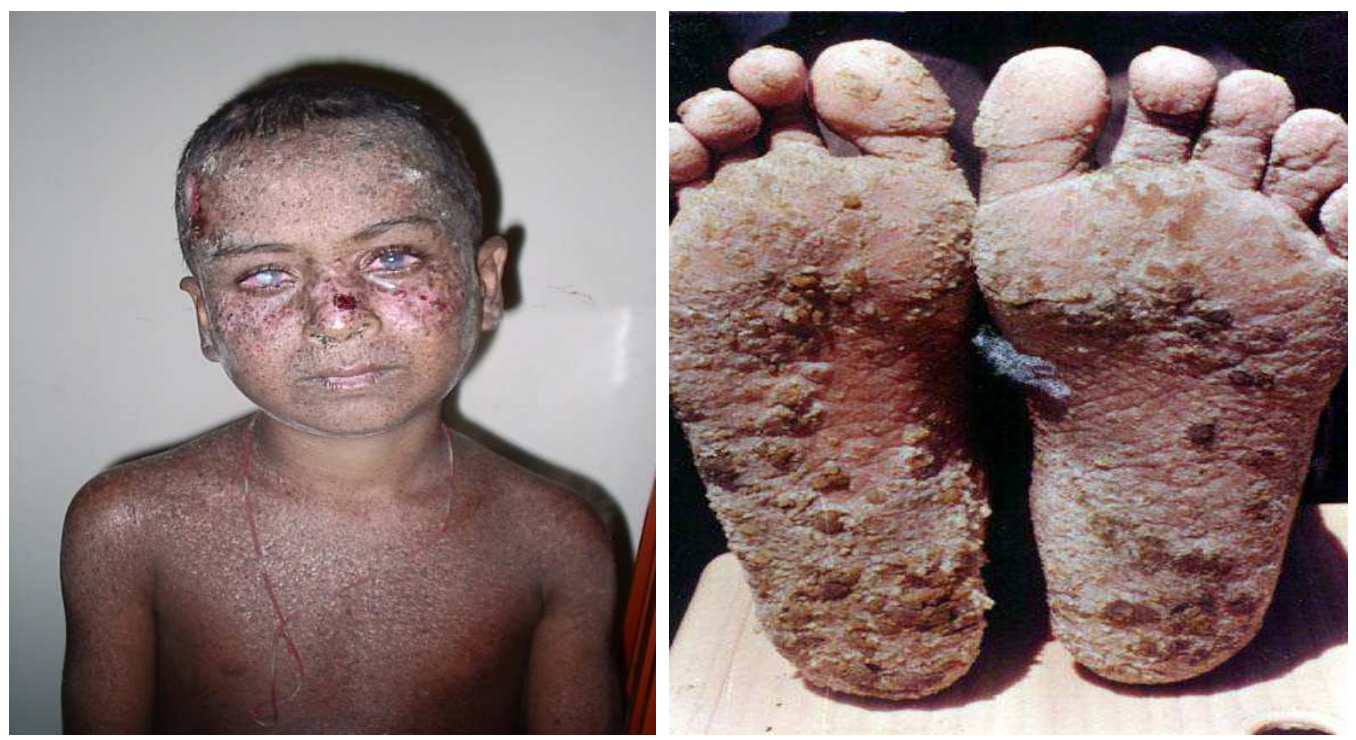

Figure 2. Arsenicosis- patients from Bangladesh 

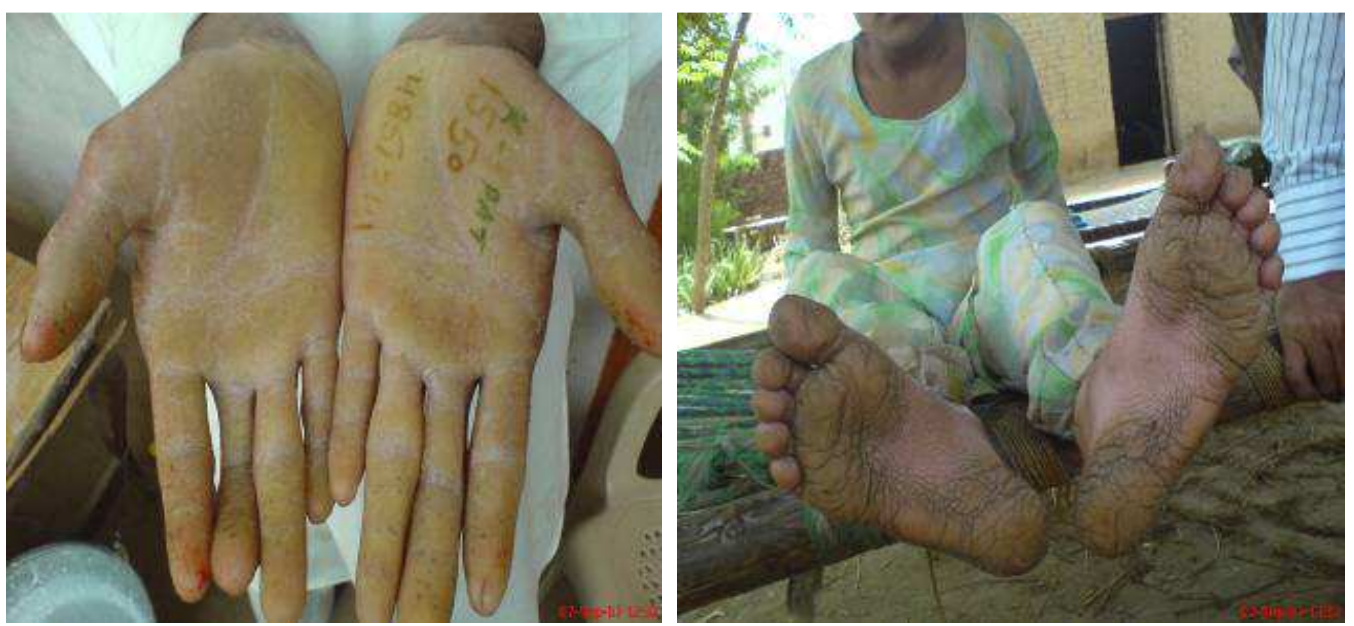

Figure 3. Suspected Arsenicosis Patients Identified in the Field - Kot Samaba , district Rahim Yar Khan -Pakistan (As 100-250\%)

During the field visits and interviewing the effected people, it was revealed that the effected people were totally ignorant about the severity of the disease and its adverse impacts on their quality of life. This all was due to lack of requisite knowledge, devoid of health facilities and illiteracy. Therefore, basing on the field tests, interviews and observations, following sample arsenicosis diagnostic and early treatment protocol has been developed;

\subsection{Arsenicosis Diagnostic Protocol}

The guidelines for diagnosis of arsenicosis are based upon symptoms of skin lesion manifestation. The diagnostic symptoms are categorized as under:

\subsubsection{Fundamental Diagnostic Symptoms Index}

- Hyperkeratosis on the palm and soles (causes are still to be elucidated)

- Hyper-pigmentation and or hypo-pigmentation that emerges on the skin of the unexposed body areas (causes yet not established)

\subsubsection{Referential Diagnostic Symptom Index}

- Peripheral neuritis, i.e. sensory and motor polyneuritis and myophagism (causes not yet known)

- Arsenic levels in urine or hair samples are significantly higher than the normal levels in non-epidemic areas of the same region

\subsubsection{Dermatological-Metamorphosis Classification}

1) Hyperkeratosis on the palms and soles

- Scattered corn like nodular hyperkeratosis on the palms and soles that are visible to the naked eye and can also be detected by pressing with the thumb.

- More and larger distinct papulous like hyperkeratosis on the palms and soles.

- Widespread maculae or streaky hyperkeratosis on the palms and the soles or several large varicose hyperkeratosis either on the palms and soles or on the dorsum of the hands and the soles, with fissuring, ulceration and bleeding in some cases.

2) Common dermatological manifestations
- Pigmentary changes in the skin or mucous membrane i.e. hyper pigmentation (melanosis),leukmelanosis.

- Hyperkeratinization, i.e. hyperkeratosis.

3) Common non-dermatological manifestations

- Weakness and asthenia.

- Conjunctival illness.

- Respiratory illness, i.e. chronic cough, bronchitis and asthma.

- Peripheral neuropathy, i.e. Tingling, Numbness, Burning and pain

4) Probable complications

- Non-pitting edema.

- Peripheral vascular disease (gangrene).

- Chronic ulcers.

- Bowen's Disease (pre-malignant skin condition).

- Squamous cell carcinoma (SCC).

- Basal cell carcinoma(bcc).

- Hepatopathy.

- Nephropathy.

- Cancer of internal organs, i.e. Urinary bladder, lung and prostate.

- Adverse pregnancy outcomes (spontaneous abortion, stillbirth and miscarriages.

- Diabetes mellitus.

- Hypertension.

\subsubsection{Evidence of Exposure}

1. History of exposure: History of consumption of arseniccontaminated water ( $>50 \mathrm{ppb}$ ) for period of exceeding six months.

2. Evidence of high levels of arsenic by biological sample analysis (BSA).

- Nail arsenic level $>1.00 \mathrm{mg} / \mathrm{Kg}$.

- Urine (in absence of intake of seafood ) arsenic level $>$ $50 \mathrm{ug} \mathrm{As} / \mathrm{L}$ is indicative of continuing exposure.

- Hair: arsenic level $>1.0 \mathrm{mg} / \mathrm{kg}$.

\subsubsection{Operational Definitions}

Pigmentary changes.

a. Hyperpigmentation ( melanosis)

- Early - Diffuse or spotted blackening of palm, trunk 
and or mucous membrane ( gum, tongue and bucal mucosa).

- Late - Extensive, diffuse or spotted dense pigmentation affecting the trunk and other parts of the body.

b. Leukomelanosis: Depigmentation in hyperpigmented areas characterized by whitish or pallor macules/patches commonly referred to as raindrop pigmentation.

\subsubsection{Hyperkeratinization of Skin (Hyperkeratosis)}

Hyperkeratinization of skin or hyperkeratosis refers to abnormally rough and dry thickening of palms and soles, which is mostly bilateral. The symptoms can be categorized as under:

- Mild - Just palpable thickening of palms and soles giving a gritty sensation on palpation, in absence of any obvious visible change.

- Moderate - Palpable and visible multiple spotted or diffuse thickening of palms and soles.

- Severe - Multiple wart or plaque like elevation (discrete/confluent) on palms and soles, and in addition may be present on other parts of the body.

\subsubsection{Miscellaneous Recommendations - Case Diagnosis}

- Establishing and maintaining an efficient and effective referral chain for clinical arsenicosis case diagnosis

- Detection and reporting of cases should be implemented
- in the light of chain of evacuation of causality.

- Health workers need to be trained as soon as possible on case detections.

- Establishment of high quality laboratories for epidemiological and diagnostic investigation.

- A multi-disciplinary, autonomous, International Centre for arsenic mitigation be established in Pakistan to act as a centre of excellence for arsenic related research.

- Issues related to arsenicosis, both clinical and public health related, should be incorporated into the curriculum of medical institutions.

- Establishment of multi-disciplinary National Task Force for the identification, formulation of strategies and monitoring mechanisms to combat the menace of arsenic contamination effectively.

- Developing social mobilization approaches including communication strategies for advocacy of decision makers at all levels and effective education /mobilization to create awareness and involvement of communities for effective programme implementation through behavioral change on use of safe water, improved sanitation and hygiene

\subsubsection{For Effective and Early Diagnosis of Arsenicosis, the following Process Flow Path Way, as Shown in Figure-4, Below is Suggested}

Process Flow Path Way - Diagnosis of Arsenicosis

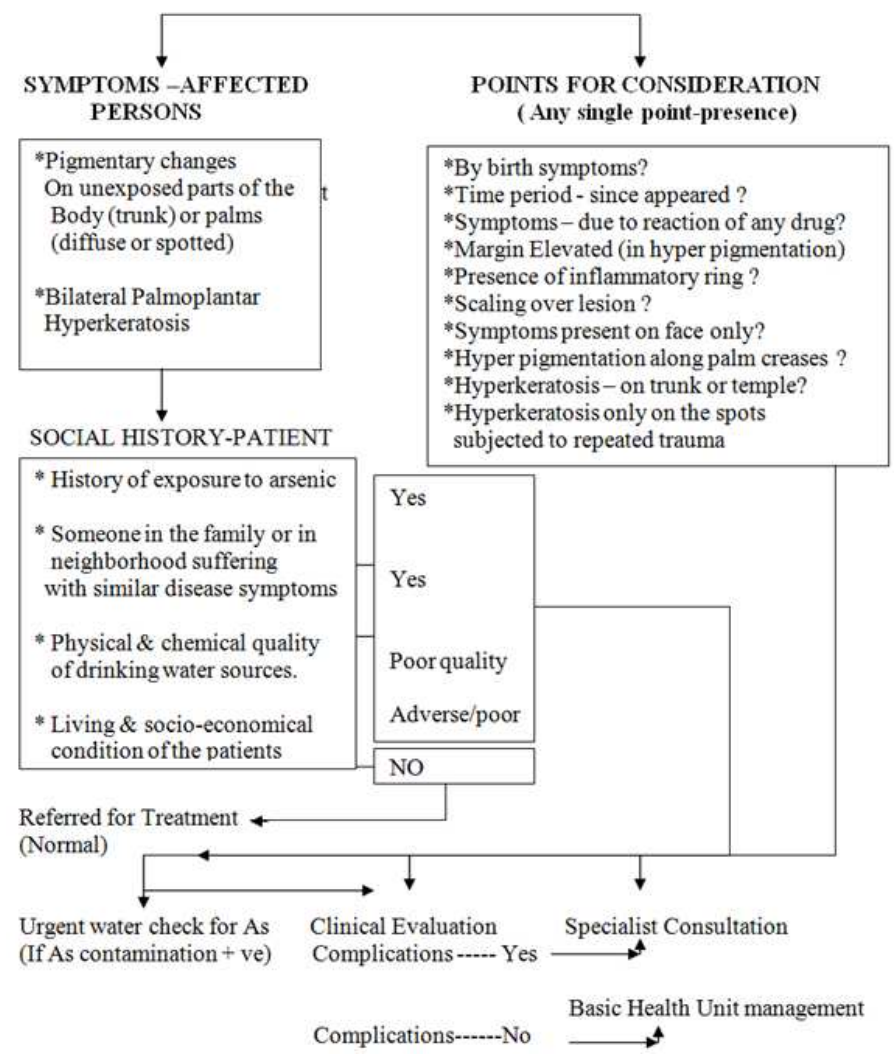

Source: Modified process path way from Bangladesh model

Figure 4. Arsenicosis early identification process flow 


\subsubsection{Arsenicosis Case Management}

After arsenicosis identification, following case management procedures be followed, as shown in figure-5, below;

\begin{tabular}{|c|c|}
\hline SYMPTOMS/MANIFESTATIONS & ACTIONS/MANAGEMENT \\
\hline $\begin{array}{l}\text { * Pigmentary appearance } \\
\text { (early or late appearance) } \\
\text { * Abnormal keratinization } \\
\text { ( Mild or moderate ) } \\
\text { * Conjunctivitis/Conjunctival } \\
\text { Congestion. } \\
\text { * Respiratory illness }\end{array}$ & $\begin{array}{l}\text { *Seize \& stop intake arsenic contaminated water } \\
\text { and switch to arsenic free safe water. } \\
\text { *Dietary supplementation. } \\
\text { *application of Keratolytic ( } 5-20 \% \text { Urea } \\
\text { Salicylicacid ointment ) for moderate keratosis. } \\
\text { *Symptomatic treatment. } \\
\text { *Follow-up and counseling with experts. }\end{array}$ \\
\hline $\begin{array}{l}\text { * Pigmentary changes including } \\
\text { leukomelanosis } \\
\text { *Severe kyperkeratinization of skin. } \\
\text { *Non-pitting oedema of legs. } \\
\text { *Peripheral neuropathy. } \\
\text { *Nephropathy (early). } \\
\text { *Hepatopathy (early) }\end{array}$ & $\begin{array}{l}\text { * Stop intake of arsenic contaminated water and switch to arsenic free safe water. } \\
\text { * Dietary supplementation. } \\
\text { * Application of Keratolytic (5-20\% Urea salicylic acid ointment). } \\
\text { * Cryosurgery/operative removal of hyperkeratosis lesion. } \\
\text { * Symptomatic treatment. } \\
\text { * Follow-up and continuous counseling with experts/specialist. }\end{array}$ \\
\hline $\begin{array}{l}\text { In addition to one or more of the above : } \\
\text { *Peripheral vascular disease including gangrene. } \\
\text { *Nephropathy (late) } \\
\text { *Hepatopathy (late). } \\
\text { *Cancer (lung, urinary, bladder, lung and prostrate) }\end{array}$ & $\begin{array}{l}\text { *Stop intake of arsenic contaminated water and take arsenic free safe water. } \\
\text { *Complication - specific management. } \\
\text { *Operative treatment. } \\
\text { * Chemotherapy \& or radiotherapy for cancers. } \\
\text { * Follow-up and continuous consultation with specialist/experts. }\end{array}$ \\
\hline
\end{tabular}

Figure 5. Arsenicosis case management path way for early treatment

\subsubsection{Behavioral Change Communication Strategies and Community Participation in Creating Awareness for safe Drinking Water}

Besides, acting and following the arsenicosis protocol, it is important to change the mind set of target communities for adopting safe health and hygiene practices . Lack of awareness, illiteracy and un-favorable socio-economic conditions make the end users in villages/rural areas the most vulnerable to the adverse effects of any type of contaminated water, including arsenic contamination. The active participation of the communities that are the intended beneficiaries of arsenic mitigation is vital for the success of the programme. Lack of awareness and generally unfavorable conditions are also create obstacles to mobilizing communities to get the best out of community-based programmes and projects. Therefore, there is a dire need to plan and implement behavioral change communication strategies for creating awareness regarding ill impacts of drinking arsenic contaminated water. The following tools are suggested which can be used through Community Based Organization ( $\mathrm{CBOs}$ ) to avoid becoming arsenicosis patients;

a. Lectures, seminars in educational institutes, like schools, colleges etc, in the target areas.

b. Stage shows / Plays and skids for the target communities.

c. TV promos and short plays.

d. Displaying posters at prominent places and preparation of booklets \& pamphlets on ill impacts of arsenic contamination . e. Establishment of community activist network who voluntarily take on the work on community mobilization and participation for community sensitization about safe drinking water .

f. The existing community level organizations can further be energized to take on the arsenic mitigation activities in their respective areas are summarized below:

- Community involvement / participation at district level headed by district health, education and community development officers for water testing /surveys. In case of arsenic detection, then exploring arsenic free alternative water supply sources.

- NGOs/CBOs/ should make use of religious places like mosques, churches and others in social mobilization, awareness and training of the masses .

- Communities should be the prime motivators and corporate / private sectors effectively be involved in fulfilling their Social Corporate Responsibilities . Under CSR , arsenic testing and setting up of arsenic removal technologies interventions can be carried out.

- Involvement of private sector in financing of well monitoring and safe water options. This should be encouraged through tax relief and other incentives

- Community capacity building by CBOs for Sample testing / survey using volunteers, teachers, health workers, schools and colleges.

- Mobilizing basic health units for early diagnosis of affected people. 


\section{Conclusion}

The causes of arsenic prevalence in groundwater can be ascertained by in-depth study / investigation of geological, geo-morphological and geo-hydrological characteristics and conditions of the arsenic contamination in affected areas. Anthropogenic activities also contribute towards ground water arsenic contamination, particularly, sustained application of fertilizers and various pesticides. Generally, the arsenic contamination takes place through food chain, soil and crops irrigated with arsenic contaminated water. Many diseases are associated with arsenic contaminated drinking water and consumption of these arsenic contaminated commodities may cause medical problems ranging from gangrene of the peripheral organs to skin cancer. But at the same time, no prudent procedures are being followed for early detection and identification of arsenicosis patients. The chronic exposure to arsenic contaminated water is dangerous and must be avoided. The well developed arsenicosis protocol for early disease detection and thereafter patient treatment administration can help in minimizing the sufferings of effected people. Besides, arsenicosis case management protocol, there is a dire need of creating awareness amongst the communities through behavioral change communication strategies for adopting improved environmental health \& hygiene conditions along with consumption of safe drinking water.

\section{References}

[1] Ahmad, T, Kahlown, M. A, Tahir, A, \& Hifza, R. (2004), "Arsenic an Emerging Issue: Experiences from Pakistan", Paper Presented at $30^{\text {th }}$ WEDC International Conference Vietiane, Lao PDR.

[2] Bhattacharya, P., Chatterjee, D. \& Jacks, G. (1996) Options to safeguard groundwater from arseniferous aquifers in West Bengal, India. In: Pickford, J. et al. (Eds.) Reaching the Unreached-Challenges for the 21st Century, Proceedings of the 22nd WEDC Conference, New Delhi, India, pp. 258-261.

[3] Bhattacharya, P., Nordqvist, S. \& Jacks, G. (1998) Soil contamination by $\mathrm{As}, \mathrm{Cu}, \mathrm{Cr}$ and $\mathrm{Zn}$ at a wood preservation site: Experimental studies of remedial techniques. Boreal Environmental Research, (in review).

[4] Bhattacharaya, P., Larsson, M., Leiss, A., Jacks, G., Sracek, A., Chatterjee, D., 1998b. Genesis of arseniferous groundwater in the alluvial aquifers of Bengal Delta Plains and strategies for low-cost remediation (abstract). In: Proc. Int. Conf. on As pollution of ground water in Bangladesh: causes, e ects and remedies. Dhaka, Bangladesh, Feb. 8-12, 1998.

[5] Dhungana J (2012), The Problem of Unhygienic Bottled Water by International Journal of Infection and Microbiology vol1, No 2, 2012,

[6] IPH (2003) Prevalence of Arsenicosis due to Ingestion of Arsenic through Drinking Water: An epidemiological Survey from Seven Districts of Punjab. Institute of Public Health, Government of Punjab (Supported by UNICEF).
[7] ICUN (2007), Bangladesh Capacity Development Action Plan for Sustainable Environmental Governance, Ministry of Environment and Forests Government of the People's Republic of Bangladesh December 2007, ISBN: 984-8574-271.

[8] Islam (2012), Islam ul Haque, Hanif W, Hasnain G \& Durez S, Socio-economic Impacts on Human Life in Arsenic Affected Area of Basti Rasul Pur, Rahim Yar Khan, Pakistan, Sustainable Agriculture Research; Vol. 1, No. 2; 2012, ISSN 1927-050X E-ISSN 1927-0518, Published by Canadian Center of Science and Education

[9] Jordan, A., F. Aslund, E. Pontis, P. Reichard, A. Holmgren 1997. Characterization of Escherichia coli NrdH.a glutaredoxin-like protein with a thioredoxin-like activity profile. J.Biol.Chem. 272:18044-18050.

[10] National Academy of Sciences. 1999. Arsenic in Drinking Water. National Research Council. National Academy Press, Washington, D.C.

[11] NAPAM (2005), National Action Plan for Arsenic Mitigation published by Ministry of Environment Government of Pakistan, Islamabad.

[12] PCRWR (2002), "Water quality status in Pakistan, 1st report 2001-2002," Pakistan Council of Research in Water Resources, 2002.

[13] PCRWR (2003a) Arsenic Contamination in Groundwater of Southern Punjab. PCRWR, Ministry of S\&T, Government of Pakistan (Supported by UNICEF).

[14] SAFWCO (2003) Survey \& Testing for Arsenic Mitigation Programme: Khairpur and Dadu Districts. Agricultural \& Forestry Workers Coordinating Organization-SAFWCO, Sindh, (Supported by UNICEF).

[15] Saldivar (2009), Andreas Saldivar \& Vicki Soto, Arsenic: An Abundant Natural Poison, ProQuest Discovery Guides http://www.csa.com/discoveryguides/discoveryguidesmain.php Released March 2009

[16] Smith T, Groen AD, Wynn JW (2000), Randomized trial of intensive early intervention for children with pervasive developmental disorder, Am J Ment Retard. 2000 Jul;105(4):269-85.

[17] USGS, 1998 (United States Geological Survey), Arctic National Wildlife Refuge, 1002 Area, Petroleum Assessment, 1998, Including Economic Analysis.

[18] USGS, 1999 (United States Geological Survey), A Summary of the U.S. Geological Survey 1999 Resource Assessment of Selected Coal Zones in the Northern Rocky Mountains and Great Plains Region, Wyoming, Montana, and North Dakota, U.S. Geological Survey Bulletin 2189, U.S. Department of the Interior, U.S. Geological Survey.

[19] U.S. Environmental Protection Agency (U.S. EPA). 1984. The development of data quality objectives. Prepared by the EPA quality assurance management staff and the DQO workgroup. U.S. Environmental Protection Agency, Washington, D.C.

[20] Wester, R.C., H.I. Maibach, et al. 1993a. In vivo and in vitro percutaneous absorption and skin decontamination of arsenic from water and soil. Fundamental and Applied Toxicology. Vol. 20, No. 3, pp. 336-340. 
[21] Wester, R.C., H.I. Maibach, et al. 1993b. Percutaneous absorption of pentachlorophenol from soil. Fundamental and Applied Toxicology. Vol. 20, No. 1, pp. 68-71.

[22] WHO Fact Sheet No. 210. (2001) Arsenic in Drinking Water.
Bulletin of the World Health Organization, Prepared for World Water Day 2001. Reviewed by staff and experts from the Programme for Promotion of Chemical Safety (PCS), and the Water, Sanitation and Health unit (WSH), World Health Organization (WHO), Geneva 78(9):1096. 